\title{
Prevalence of childhood maltreatment among college students in Erbil, Iraq
}

\author{
B.A. Saed, ${ }^{1}$ L.A. Talat ${ }^{2}$ and B.A. Saed ${ }^{3}$
}

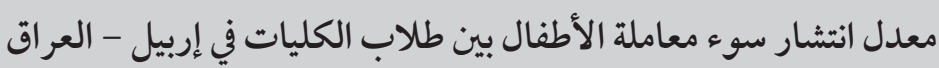

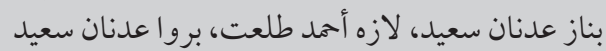

الخلاصـة: لم يحظ سوء معاملة الأطفال بقدرٍ كافٍ من البحوث في منطقة كردستان العراق. لذلك أجرى الباحثون دراسة مستعرضة لقياس تكرار

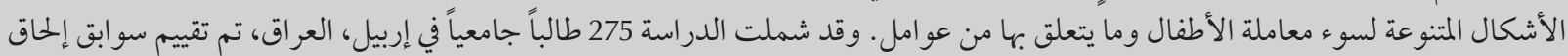

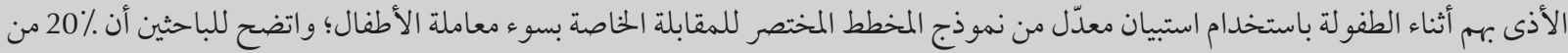

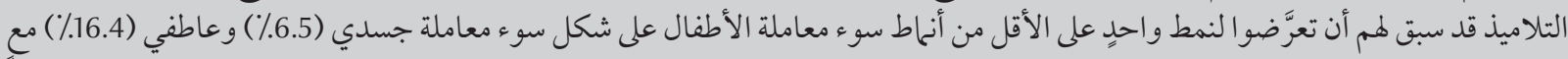

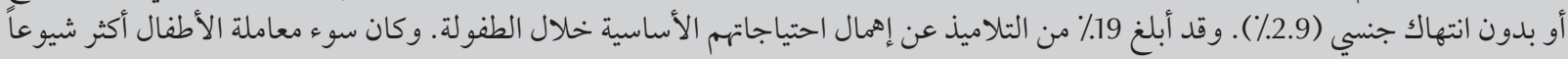

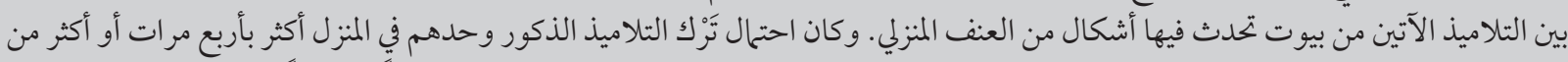

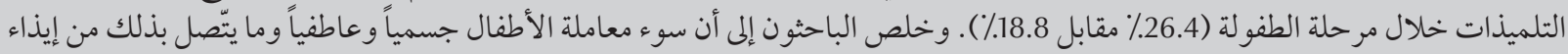

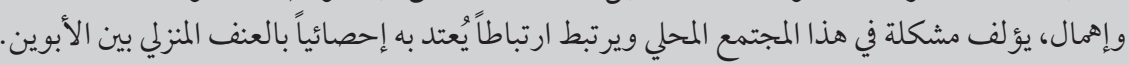

ABSTRACT Child maltreatment has not been adequately researched in the Kurdistan region of Iraq. In a crosssectional study to measure the frequency of different forms of maltreatment in childhood and its related factors, 275 college students from Erbil, Iraq were assessed for a history of childhood abuse using a questionnaire adapted from the Childhood Maltreatment Interview Schedule-Short Form. Of the students, 20.0\% had a history of exposure to at least 1 type of childhood maltreatment in the form of physical (6.5\%), emotional (16.4\%) and/or sexual (2.9\%) abuse. Neglect of their basic needs during childhood was reported by $19.0 \%$ of students. Childhood abuse was significantly more common among students coming from homes with domestic violence. Male students were significantly more likely to be left alone at home 4 times or more during childhood than were females (26.4\% versus $18.8 \%$ ). Childhood physical and emotional abuse and neglect is a problem in this community and there are significant correlates with the occurrence of intimate partner violence.

\section{Prévalence de la maltraitance dans l'enfance chez des étudiants de I'Université d'Erbil (Iraq)}

RÉSUMÉ La maltraitance des enfants n'a pas été suffisamment étudiée dans la région du Kurdistan iraquien. Dans une étude transversale visant à mesurer la fréquence des différentes formes de maltraitance dans l'enfance et les facteurs associés, 275 étudiants d'Erbil (Iraq) ont été interrogés sur leurs antécédents de maltraitance dans l'enfance à l'aide d'un questionnaire adapté de la version abrégée du Childhood Maltreatment Interview Schedule. Parmi les étudiants, 20,0\% ont été exposés à au moins un type de maltraitance, d'ordre physique (6,5\%), psychologique (16,4\%) et/ou sexuel (2,9\%). La négligence de leurs besoins fondamentaux pendant l'enfance a été rapportée par 19,0 \% des étudiants. Les mauvais traitements étaient nettement plus fréquents chez les étudiants issus de familles où la violence domestique était présente. Les garçons étaient au moins quatre fois plus susceptibles d'avoir été laissés seuls au domicile pendant leur enfance que les filles (26,4\% contre 18,8 \%). Les mauvais traitements physiques et psychologiques ainsi que la négligence représentent un problème dans cette communauté et sont souvent significativement corrélés avec des cas de violence exercée par le partenaire intime. 


\section{Introduction}

Child maltreatment includes both the abuse and the neglect of a child, which are different types of problems with slightly different causes, perpetrators and outcomes. Furthermore, abuse occurs in a number of different forms including physical abuse, psychological maltreatment and sexual abuse. These categories of abuse are fairly common across cultures [1]. It has become widely accepted that child abuse by parents or caregivers is more common worldwide than previously acknowledged [1]. In the United States (US), the Centers for Disease Control and Prevention defines child maltreatment as "Any act or series of acts of commission or omission by a parent or other caregiver (e.g., clergy, coach, and teacher) that results in harm, potential for harm, or threat of harm to a child" [2]. Acts of commission are divided into physical, sexual and psychological abuse, while the acts of omission are classified as physical, emotional, medical or educational neglect or failure to supervise. Neglect is defined as "failure to provide for a child's basic physical, emotional, or educational needs or to protect a child from harm or potential harm" [2].

The National Child Abuse and Neglect Data Survey (NCANDS) in 2004 estimated that $1.2 \%$ of children were maltreated in the US [3]. In addition, the superior National Incidence Study (NIS) methodology suggested that $2.3 \%-4.2 \%$ of children in the US were maltreated each year [4]. Exposing children to intimate partner violence, especially frequent or severe cases, has been conceptualized by some as a form of child maltreatment $[4,5]$. Indeed, the national representative surveys that have been conducted indicate that child maltreatment is much more prevalent than that reported in the NIS and NCANDS surveys [6-9]. A study examining the risk factors for child maltreatment found that the influence of sociodemographic risk factors on the occurrence of maltreatment varied by type of maltreatment. This lack of uniformity in the effects of sociodemographic risk factors suggests that each type of maltreatment has a somewhat distinct etiology [10].

The aim of the present retrospective study in Iraq was to ascertain the frequency of maltreatment during childhood and adolescence in a sample of college students and also to evaluate the presence of any correlation between different sociodemographic variables with the occurrence of maltreatment.

\section{Methods}

\section{Study setting and sample}

In this cross-sectional study, a random sample of 300 male and female students was selected from 4 colleges (colleges of Education, Art, Nursing and Medicine) in Erbil, Iraq, in the period between March and June 2011. Students who were 18 to 25 years old were included in this study after obtaining their consent and explaining that their participation was voluntary and that their answers would be kept confidential. All procedures in this study were conducted after obtaining approval from the Medical Ethics Committee at the College of Medicine, Hawler Medical University.

\section{Data collection}

History of 4 types of child abuse (physical, sexual, domestic violence and neglect) was assessed using a questionnaire adapted from the Childhood Maltreatment Interview ScheduleShort Form [11] after translating it into Kurdish. Presence of child supervision neglect was assessed by asking how often the students were left home alone or had their basic needs (being kept clean or being given food or clothing) neglected during childhood. We also asked them about their current health status in order to determine if poor health in the future was an associated outcome of childhood maltreatment.
Demographic data related to students and their parents were collected, such as marital status, employment status and parents' education. Five parameters were used to score the socioeconomic status of the family, each parameter scored as follows: home ownership (rental $=0$, own $=1$ ); family members per bedroom $(>4=0,3-4$ $=1,1-2=2$ ); educational level (illiterate $=0$, primary $/$ intermediate school $=$ 1 , high school $/$ institute $=2$, college $=$ 3 ); occupation (jobless $=0$, unskilled $=1$, skilled wage earner $=2$, professional $=3$ ); income per month (dinars $50000-150000=0,150000-250000$ $=1,250000-350000=2,>350000=$ $3)$. Based on these parameters, a total score for socioeconomic status was calculated and classified into low (0-4), intermediate (5-7) and high (>7) [12].

\section{Statistical analysis}

Statistical analysis was performed using SPSS, version 17.0 for Windows. For descriptive purposes, quantitative variables were presented as mean and standard deviation (SD), and qualitative data were reported in terms of rates and proportions. For analytic purposes, independent sample $t$-test, chi-squared and Fisher exact tests were utilized. A $P$-value of $\leq 0.05$ was considered statistically significant.

\section{Results}

\section{Student's background characteristics}

Out of the 300 students who received the questionnaire, 275 students returned completed questionnaires. The mean age of students was 22.1 (SD 1.7) years, ranging between 17 and 30 years of age; $94(34.2 \%)$ were male and 181 (65.8\%) were females; 35 (12.7\%) of the students were married, 114 (41.5\%) came from rural areas and the majority of the students (88.0\%) were living in a home owned by them or their parents. While more than half of the students 
felt they were currently in good health, 14 (5.1\%) perceived their own health status to be bad (Table 1).

\section{Parents' background characteristics}

For 27 of the students (9.8\%) 1 or both parents had died before they were age 17 years (6 had lost their mother, 19 their father and 2 students had lost both parents). Only 4 (1.5\%) had parents who had separated before age 17 years, $5(1.8 \%)$ of the students had parents with alcohol or drug addiction problems and 12 (4.4\%) had parents with mental diseases, of which 6 were receiving psychiatric treatment.

The study showed that 62 (22.5\%) of the students had witnessed their father hitting their mother, and in 5 of these cases the mother needed medical intervention. Male students were significantly more likely to report a parent assaulting the other (30.9\% of male students versus $18.4 \%$ of female students $)(P=0.02)$.

As seen in Figure 1, more students recalled feeling much care and love (very much/plenty) from their mothers (87.9\%) than from their fathers (79.8\%). Students coming from families with high socioeconomic status were significantly more likely to feel care and love from their parents before the age of 17 years old compared with students from poor families $(P=0.008)($ Table 2$)$.

\section{Prevalence of and types of abuse suffered}

Of the 4 types of childhood abuse measured in this study, $20.0 \%$ of our sample reported exposure to at least 1 type of abuse, $8.9 \%$ had been exposed to 2 types and $3.6 \%$ of the students had been exposed to 3 types of childhood abuse.

Physical abuse before the age of 17 years was reported by $18(6.5 \%)$ of the participants, with 13 (4.7\%) of students recalling being hit, pushed or punched by their fathers before the age of 17 years, 4 of whom were hurt to the degree that they needed medical intervention. Physical abuse was reported

\begin{tabular}{|c|c|c|}
\hline Variable & No. of students & $\%$ \\
\hline \multicolumn{3}{|c|}{ Socioeconomic status $(n=273)^{a}$} \\
\hline Low & 49 & 17.9 \\
\hline Intermediate & 83 & 30.4 \\
\hline High & 141 & 51.6 \\
\hline \multicolumn{3}{|l|}{ Smoking status } \\
\hline Current smoker & 11 & 4.0 \\
\hline Previous smoker & 13 & 4.7 \\
\hline \multicolumn{3}{|l|}{ Other substance use } \\
\hline Alcohol & 6 & 2.2 \\
\hline Tranquilizers & 4 & 1.5 \\
\hline Prescribed pain killers & 86 & 31.3 \\
\hline Antidepressants & 4 & 1.5 \\
\hline \multicolumn{3}{|c|}{ Perception of general health status } \\
\hline Bad & 14 & 5.1 \\
\hline Good & 154 & 56.0 \\
\hline Very good & 81 & 29.5 \\
\hline Excellent & 26 & 9.5 \\
\hline
\end{tabular}

${ }^{a}$ Data on socioeconomic status missing for 2 cases. by a higher proportion of the students who had witnessed their fathers hitting their mothers $(10 / 65,16.1 \%)$ compared with those having no history of such intimate partner violence $(8 / 213$, $3.8 \%)(P=0.002)$.

Sexual abuse was reported by 8 (2.9\%) students and, similarly, sexual abuse was significantly more likely to be seen among students with a history of parents' physical assaulting each other $(5 / 62,8.1 \%)$ than students who did not recall such an event $(3 / 213,1.4 \%)(P$ $=0.017$ ).

Regarding emotional abuse, only 262 students responded to these questions, out of whom 43 (16.4\%) met the criteria for this type of maltreatment.

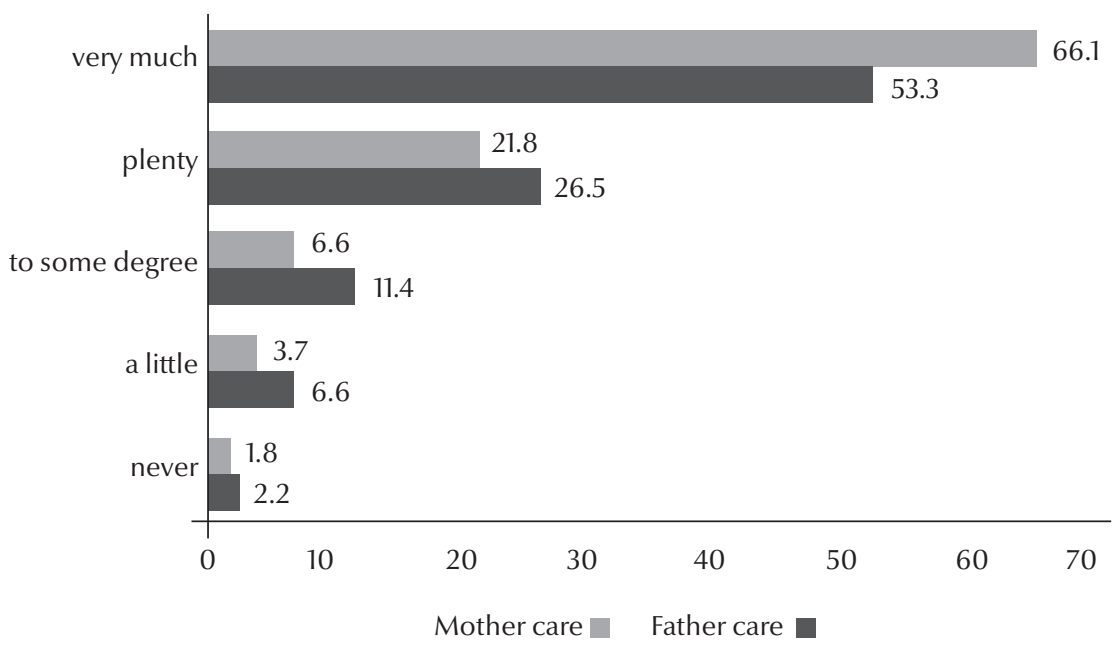

Figure 1 Percentage of students who felt care and love from their parents during their childhood $(n=274)$ 


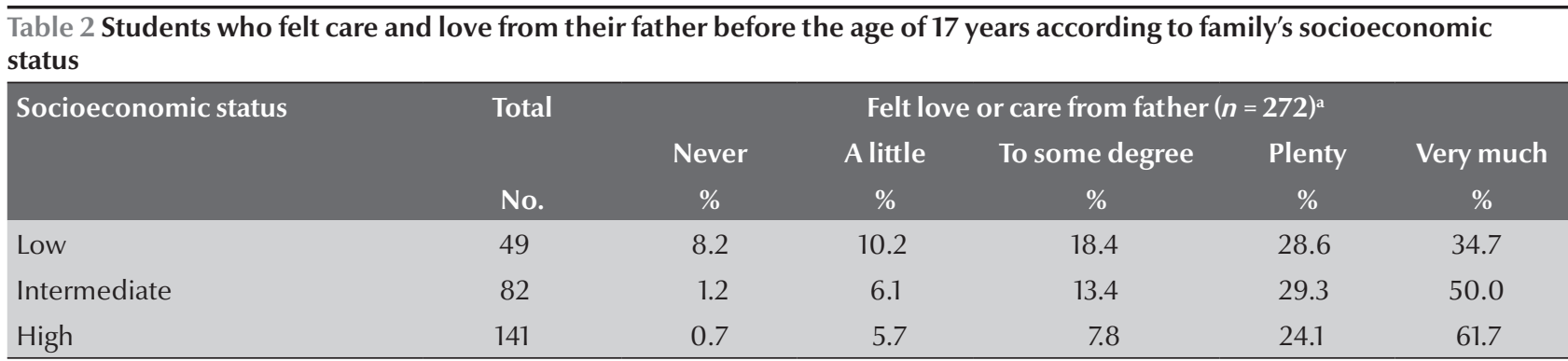

${ }^{a}$ Data on socioeconomic status or feeling love missing for 3 cases.

Table 3 shows the frequencies of different emotional assaults recalled by students as occurring before their 17th year. Parents' criticism and shouting at children were the most frequent forms of emotional abuse compared with other forms and was reported to have occurred $>20$ times/year in $30.0 \%$ and $25.9 \%$ of the students respectively. It was noted also that $41.9 \%$ of students who had suffered emotional abuse also reported a history of domestic violence among their parents, and this was found to be statistically significant $(P<0.001)$. In addition, parents were significantly more likely to criticize male children than female children (reported by $75.3 \%$ of males versus $56.2 \%$ of females $)(P=0.002)$.

Of the 268 students who responded $51(19.0 \%)$ felt that their parents had ever neglected their basic needs such as food and hygiene during their childhood, with $6.5 \%$ of the students reporting that their basic needs were neglected 4 times or more. In addition, 57 (20.7\%) of the students recalled being left alone at home by their parents $4+$ times before the age of 17 years. Male students were significantly more likely to be left alone at home $4+$ times before age 17 years compared with females (26.4\% versus $18.8 \%)(P=0.02)$.

\section{Discussion}

Although numerous studies have been conducted on the prevalence and cooccurrence of different forms of childhood maltreatment, the present study, to the authors' knowledge, is the first attempt to assess types of child abuse experienced by college students in Erbil, Iraq. In this study, $20.0 \%$ of students had experienced at least 1 type of abuse and $11.6 \%$ reported having been exposed to 2 or more types of maltreatment, with a significant correlation of all forms of maltreatment with one another. A similar study by Clemmons et al. in Texas, United States, found a high proportion of students (29\%) with a history of exposure to 2 or more forms of abuse during childhood [13].

Physical abuse before the age of 17 years was reported by $6.5 \%$ of the participating students. This proportion is slightly lower than reported in similar studies in Texas and Croatia, in which $10.7 \%$ and $15 \%$ respectively of the participants reported physical abuse during childhood $[13,14]$. This may be due to the cultural differences in the methods used for punishing children. Furthermore, differences in the prevalence might be attributed to the low sample size and failure to report all cases of abuse by the students due to social embarrassment or feelings of shame [10].

Physical abuse was recorded more among the students who witnessed their fathers hitting their mothers compared with those having no history of intimate partner violence in the family. These results agree with the conclusions of a literature review by Appel and Holden who observed that marital violence and child abuse are likely to co-occur [15].

\begin{tabular}{|c|c|c|c|c|c|c|c|}
\hline \multirow[t]{3}{*}{ Type of emotional abuse } & \multicolumn{7}{|c|}{ No. of times per year abuse experienced } \\
\hline & $\mathbf{0}$ & 1 & 2 & 3-5 & 6-10 & 11 & $>20$ \\
\hline & $\%$ & $\%$ & $\%$ & $\%$ & $\%$ & $\%$ & $\%$ \\
\hline Shouted at & 23.7 & 18.4 & 12.0 & 11.3 & 3.4 & 5.3 & 25.9 \\
\hline Insulted & 48.5 & 24.4 & 6.5 & 4.2 & 3.1 & 2.3 & 11.1 \\
\hline Criticized & 23.2 & 13.1 & 9.0 & 7.1 & 13.1 & 4.5 & 30.0 \\
\hline Made to feel guilty & 37.4 & 22.6 & 10.2 & 9.1 & 3.0 & 2.6 & 15.1 \\
\hline Humiliated & 40.0 & 22.3 & 11.3 & 7.5 & 3.0 & 4.2 & 11.7 \\
\hline Embarrassed in front of others & 46.4 & 28.0 & 9.6 & 4.6 & 3.1 & 2.3 & 6.1 \\
\hline Made to feel a bad person & 51.0 & 28.0 & 7.3 & 4.2 & 1.9 & 2.7 & 5.0 \\
\hline
\end{tabular}


Previous studies demonstrated that $30 \%-60 \%$ of children whose mothers were victims of domestic violence were also being abused [16]. It is also important to acknowledge that there is debate about whether a child's witnessing violence should itself be considered a form of child maltreatment. Children in families with a history of domestic violence are at increased risk for all form of child abuse. This means that conflicts and tensions between parents can negatively correlate with the quality of parenting by both mothers and fathers. The prevalence of domestic violence in Erbil was reported in a previous study in 2008 to be $21.6 \%$ [17]. A more recent study found that $58 \%$ of the women had experienced psychological abuse, 39\% experienced physical abuse and $21 \%$ experienced sexual abuse by partner [18]. This may indicate that violence is common in Kurdish societies and this may have an impact on children living in these families. The Iraqi family health survey which was conducted during 2006 and 2007 showed that $17.6 \%$ of women in Kurdistan region reported emotional violence and $10.9 \%$ reported physical violence by their husbands [19]. This may indicate that the reported rate of violence is increasing and we need greater efforts to provide a healthy environment in which children can grow and to increase parents' awareness of the impact of domestic violence.

Students coming from families of high socioeconomic status were significantly more likely to feel care and love from their parents before the age of 17 years old. On the other hand, this study did not show a statistically significant association between physical or sexual abuse and socioeconomic status. A British population-based survey of 7353 persons also found no association between severe sexual abuse in childhood and social class [20]. In addition, a study by Hussey et al. in the United States found no association between family income and physical abuse and that family income was independently associated with sexual abuse [10].

A small proportion $(2.9 \%)$ of the students in this sample reported sexual abuse during childhood. Although this prevalence of sexual abuse is comparable to other studies in the United States and Germany $[6,7,21]$, the results are lower than those reported by students from Latina colleges in Texas, in which $38.4 \%$ had a history of sexual abuse during their childhood [13]. Such differences might be due to cultural variations between the studied samples.

While $20.7 \%$ of the students recalled being left alone at home by the parents 4+ times before the age of 17 years, male students were significantly more likely to be left alone at home during childhood compared with females. A similar survey in the US found that $21.3 \%$ of the students recalled being left alone many times during their childhood [7]. A history of childhood neglect among students in this study was more common in comparison with other types of abuse. Supervision neglect can represent around 30\% of cases of maltreatment in childhood [22]. Meanwhile, a study in the Kurdistan province of the Islamic Republic of Iran found that the rate of child neglect to be as high as $80 \%$. This may be attributed to measures used for assessment of neglect which still has no unified definition [23]. Male students in our study were more likely to report being neglected during childhood by their caregiver. This agrees with a survey done in the United Kingdom [24]. This may be attributed to cultural norms in which boys are believed to need less supervision than girls.

Emotional abuse in this study was reported in $16.4 \%$ of the students and was the most frequent form of abuse among the college students. This finding is agreement with another study in Germany which $15 \%$ of students reported emotional abuse [21]. However, other studies in Texas and US army installations in Germany found a reported prevalence of emotional abuse in childhood of $27 \%$ and $26 \%$ respectively among students $[13,25]$.

We should bear in mind some limitations to the current study. There are potential sources of recall error in the retrospective recording of childhood experiences and the possibility of false-negative statements, due to unconscious (memory suppression) or conscious (shame) motives, has been discussed exhaustively in the literature [26]. Another limitation of the present study involves the use of a college sample; despite being the most well-studied group within the child maltreatment literature, samples of college students have limited variance in terms of age, educational status and socioeconomic status [27], and therefore may not be representative of the whole population.

In Kurdistan, there are a few nongovernmental women's organizations working on domestic violence in coordination with the Kurdistan ministries of health and justice. Their main objectives are to provide awareness courses, open shelters for the victims of violence and organize training courses for doctors and medical staff to counsel victims. Meanwhile, there have been limited efforts made to deal with the issue of child abuse, with no specific law to protect children against abuse and neglect. Part of these intervention strategies should include reducing the prevalence of domestic violence in this community as it has been associated with all 3 types of maltreatment. Therefore, it is important to provide proper counselling regarding intimate partner violence and help parents understand its impact on childhood maltreatment. The findings in this study can help inform intervention strategies by alerting public health and social workers to the impact of this issue, in order to reduce the possible effects of childhood maltreatment on the health and wellbeing of these cases.

Competing interests: None declared. 


\section{References}

1. Schwartz-Kenney BM, McCauley M, Epstein M, eds. Child abuse: a global view. Westport, Connecticut, Greenwood Press, 2001.

2. Leeb RT et al. Uniform definitions for public health and recommended data elements. Version 10. Atlanta, Georgia, Centers for Disease Control and Prevention, National Center for Injury Prevention and Control, 2008.

3. Child maltreatment 2004. Washington DC, United States Department of Health and Human Services, Administration on Children, Youth and Families, 2006.

4. Sedlak AJ, Broadhurst DD. The Third National Incidence Study of Child Abuse and Neglect: final report. Washington DC, United States Department of Health and Human Services, 1996.

5. Graham-Bermann SA. The impact of woman abuse on children's social development: research and theoretical perspectives. In: Holden GW, Geffner R, Jouriles EN, eds. Children exposed to marital violence: Theory, research, and applied issues. Washington DC, American Psychological Association, 1998:21-54.

6. Finkelhor D, Dziuba-Leatherman J. Children as victims of violence: a national survey. Pediatrics, 1994, 94:413-420.

7. Gallup Organization. Disciplining children in America: a Gallup poll report. Princeton, New Jersey, Gallup Organization, 1995.

8. Diaz A, Simantov E, Rickert VI. Effect of abuse on health: results of a national survey. Archives of Pediatrics and Adolescent Medicine, 2002, 156:811-817.

9. Briere J, Elliott DM. Prevalence and psychological sequelae of self-reported childhood physical and sexual abuse in a general population sample of men and women. Child Abuse and Neglect, 2003, 27:1205-1222.

10. Hussey JM, Chang JJ, Kotch JB. Child maltreatment in the United States: prevalence, risk factors, and adolescent health consequences. Pediatrics, 2006, 118:933-942.

11. Briere J. Child abuse trauma: theory and treatment of the lasting effects. Newbury Park, California, Sage Publications, 1992.

12. Al-Mashadani JS. Hepatitis B virus markers in diabetics [MSc thesis]. Baghdad, University of Baghdad, 1988.

13. Clemmons JC et al. Co-occurring forms of child maltreatment and adult adjustment reported by Latina college students. Child Abuse and Neglect, 2003, 27:751-767.

14. Aberle $\mathrm{N}$ et al. Emotional and physical abuse in family: survey among high school adolescents. Croatian Medical Journal, 2007, 48:240-248.
15. Appel AE, Holden GW. The co-occurrence of spouse and physical child abuse: A review and appraisal. Journal of Family Psychology, 1998, 12:578-599.

16. Edleson JL. Studying the co-occurrence of child maltreatment and domestic violence in families. In: Graham-Bermann SA, Edleson JL, eds. Domestic violence in the lives of children: the future of research, intervention, and social policy. Washington DC, American Psychological Association, 2001:91-110.

17. Kareem H. Domestic violence a field works in the city of Erbil. Iraq, Erbil, Iraq, Ministry of Culture Press, 2008:189-246 [in Arabic].

18. Hoshyar $\mathrm{H}, \mathrm{Al}$-Taweel NG. Prevalence of violence and factors associated with violence among a group of married women in Erbil [MSc thesis]. Erbil, Iraq, Hawler Medical University, 2011.

19. Republic of Iraq: Iraq Family Health Survey 2006/7. World Health Organization, Regional Office for Eastern Mediterranean [website] (http://www.emro.who.int/iraq/pdf/ifhs_report_en.pdf, accessed 16 January 2013).

20. Bebbington PE et al. Child sexual abuse reported by an English national sample: characteristics and demography. Social Psychiatry and Psychiatric Epidemiology, 2011, 46:255-262.

21. Häuser W et al. Maltreatment in childhood and adolescence: results from a survey of a representative sample of the German population. Deutsches Ärzteblatt International, 2011, 108:287-294.

22. Coohey C. Making judgments about risk in substantiated cases of supervisory neglect. Child Abuse and Neglect, 2003, 27:821-840.

23. Sheikhattari P et al. Child maltreatment among school children in the Kurdistan Province, Iran. Child Abuse and Neglect, 2006, 30:231-245.

24. Cawson P et al. Child maltreatment in the United Kingdom: a study of the prevalence of child abuse and neglect. London, $\mathrm{Na}$ tional Society for the Prevention of Cruelty to Children, 2000.

25. Jellen LK, McCarroll JE, Thayer LE. Child emotional maltreatment: a 2-year study of US Army cases. Child Abuse and Neglect, 2001, 25:623-639.

26. Hardt J, Rutter M. Validity of adult retrospective reports of adverse childhood experiences: review of the evidence. Journal of Child Psychology and Psychiatry, and Allied Disciplines, 2004, 45:260-273.

27. Rind B, Tromovitch P, Bauserman R. A meta-analytic examination of assumed properties of child sexual abuse using college samples. Psychological Bulletin, 1998, 124:22-53. 